\title{
The Use of Medicinal Plants in Common Ophthalmic Disorders: a Systematic Review With Meta-analysis
}

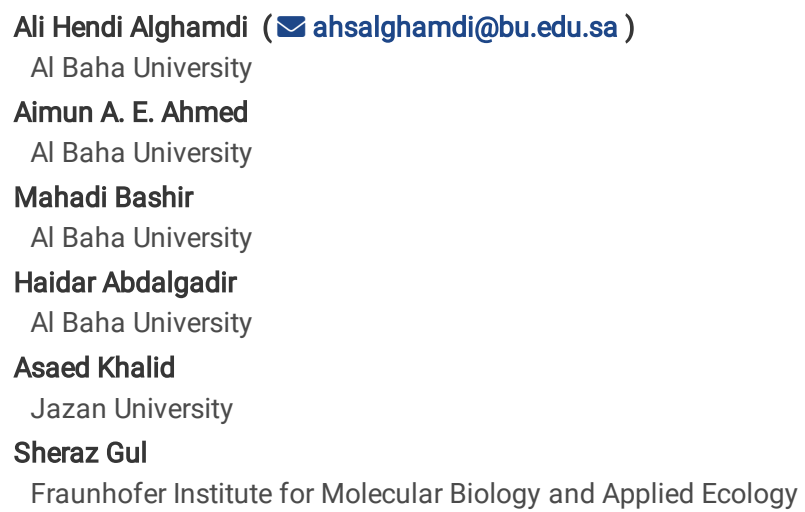

Research Article

Keywords: Medicinal Plants, Ophthalmic, Systematic review, Meta-analysis, Forest plot, Funnel plot, Prisma Chart

Posted Date: February 16th, 2022

DOI: https://doi.org/10.21203/rs.3.rs-1172751/v1

License: (c) (1) This work is licensed under a Creative Commons Attribution 4.0 International License. Read Full License 


\begin{abstract}
Background: There is rare information regarding the use of Medicinal Plants For Ocular Diseases. This study aimed to assess and compile the available research articles about medicinal plants used for ocular diseases.
\end{abstract}

Methods: The PICOS as a search term were used to design a clear answerable study question. the studies were retrieved by searching in four selected databases; PubMed, science direct, and the American Academy of Ophthalmology (AAO), using well-designed and optimized filters. while the Prisma flowchart was applied and the quality of the included studies was assessed. meta-analyses were performed to calculate the pooled odds ratios (ORs) or standardized mean (SM) for included studies for each outcome, using both fixed and random-effect approaches through constructing the relevant forest plot. the heterogeneity of the studies was determined by estimating both $\mathrm{Q}$ and $\mathrm{I}^{2}$ parameters. Moreover, the funnel plot was used to test the publication bias.

Results: A Prisma flow chart revealed that; a total of 2,949 articles were retrieved, 35 full-text were assessed for eligibility and seven studies (4 observational and 3 experimental) with low to moderate quality were eligible and involved in the systematic review with a total of 600 plants from 4 countries. Among the 600 plants, only 24 (4\%); were used to assess the status, both the fixed and random models of the studies proved that, the included studies have a tendency to predict the outcomes for the observational studies $(\mathrm{OR}=0.062, \mathrm{Cl}=0.043-0.090$ and $\mathrm{OR}=0.039, \mathrm{Cl}=0.012-0.122)$ for different plants used for ocular diseases. High heterogeneity (estimated as $I^{2}=87.078$, Tau $^{2}=1.161$ and Q-value $=23.217$ with $p$-value of 0.000$)$. whilst for experimental studies $\left(I^{2}=94.928\right.$, Tau ${ }^{2}=$ 23.211 and Q-value $=39.434$ with $p$-value of 0.000 ) and publication bias were reported.

Conclusions: Few articles that represent about 600 plants with low to moderate quality reported the use of medicinal plants for ocular diseases. The metaanalysis confirmed the systematic review findings regarding the plants' traditional use with high heterogeneity and publication bias. A considerable gap was proved towards the use of medicinal plants in ocular diseases that require intensive research.

\title{
1. Introduction
}

\subsection{Systematic reviews and Meta-analysis as a recent, powerful research tool}

\author{
A-Systematic reviews: A qualitative part
}

The systematic review is a rigorous process of searching, selecting, appraising, interpreting, and summarizing results from original published studies on a specific topic. These original studies may be observational studies or randomized trials. The study summaries may be qualitative or quantitative. If a systematic review Involves a quantitative summary of results, it is called a meta-analysis(1).

Prior to initiating a systematic review, a protocol incorporating specific plans with sufficient clarity should be developed for each systematic review step to ensure the quality of the systematic review process and provide rigor and guidance (2).

Systematic reviews are conducted to answer specific, often narrow, clinical questions in depth. These questions can be formulated according to four main components, collectively named PICO(3). The main goals of systematic reviews are combined results in a way that reduces the probability of chance observations affect clinical practice, to detect defects in the literature that might not be seen by only examining individual studies(1) and can also help to identify further areas of research (3). The evaluation of the methodological quality of studies is an essential step to examine variation in the quality of included studies involved in systematic reviews(4). Assessment of methodological quality involves evaluation of internal(5).and external validity (generalizability, applicability)(6-8), as well as study design and conflict of interest in the conduct of the study. (9)

The risk of bias is a systematic error or deviation from the truth. In results or inferences, five types of bias must be assessed in systematic review study according to Cochrane collaboration groups; selection(7), performance(10)., detection(9), attrition(7) and reporting bias (10). (11). Also, Confounding bias: A confounder is an extraneous variable whose presence affects the variables being studied. The results do not reflect the actual relationship between the variables under study. This bias can be eliminated within the study design by using randomization, restriction, and matching. Statistical methods as multivariate models can use after data gathering to control the confounders(12).

\section{B- Meta-analysis "The analysis of analyses": A quantitative part}

Meta-analysis is a statistical technique used to combine and synthesize the data from several studies into a single quantitative estimate or summary effect size to reduce bias and examine the heterogeneity of individual study results(13). Meta-analyses play a central role in developings the impact of the results after adjustment of one or more characteristics of the studies(3). The strength of inference is greater if the results are unchanged under varying conditions(1). A sensitivity analysis is used to determine if the result of meta-analysis changes when different decisions related to the systematic review/meta-analysis process are made. For example, a sensitivity analysis could be conducted to determine if a fixed-versus random-effects analysis reach different conclusions(14).

\subsection{Medicinal plants and Ophthalmic disorders or Traditional eye medicines}

\section{A- Ethnobotany as a major drug Source}

Martin, 1995 defined ethnobotany as "all studies concerning plants", which describe local people's interaction with the natural environment(15).

As a discipline of ethnobotany, traditional herbal medicine refers to the therapeutic values of herbal medicine beyond the medication's active ingredients. Traditional herbal medicine is the oldest known type of medical treatment and has been practiced in virtually every culture worldwide(16) 
On the basis of ethnomedicinal and random plant collection approaches for searching out new pharmacologically bioactive agents. Folkloric information from many different cultures is an essential tool in revealing plants with useful medicinal properties (17).

Although plants possess immense traditional applications but a few species have been screened for their biological activity; moreover, a lack of such information obviously regarding ocular disorders.

\section{B- Cross-sectional survey as a common Ethnobotanical study design:}

Unlike a longitudinal study, Cross-sectional is a quantitative survey possible at one point in time. Where four-step approach was applied; use of random sampling for more rigorous statistical analysis and to allow the generalization of conclusions about larger populations. Snowball of randomly selected informants sampling(18). In this historical perspective, the eldest persons in the study area who might know something about the history contact all persons who have essential functions related to gardening in the study area for socioeconomic conditions in the study area(19).

During the conduction of cross-sectional observational of ethnobotanical survey; Informants' observation is one of the best ways to study the transmission of knowledge, While quantitative data on the abundance of plant uses are critical for comparative purposes.

Informal and formal techniques were used to collect both qualitative and quantitative data in ethnobotany.

For re-synthesis of DATA for meta-analysis purposes, a quantitative ethnobotanical DATA is required where specific types of indices such as; Relative frequency citation(RFC), Informant Consensus Factor (ICF), Medicinal Use Value (MUV), Use reports (UR), and others must be used(20, 21).(21-23)

\section{C- Common Ocular disorders}

Commonly, several eye troubles that can be categorized as; (i) Eye infections due to pathogenic microorganisms invade any part of the eyeball or proximate area. The infection leading to pain, redness, discharge, watering, and light sensitivity (ii) Eye disorders including; cataract, dry eyes, and eye allergies and, (iii) Vision damage such as; glaucoma, Diplopia (24)[Haddrill, 2009].

Glaucoma is a neurodegenerative condition that damages the main nerve to the eye (Optic nerve) that located in the back of the eye and responsible for transmitting electrical impulses to the brain [Kumarasamyv et al 2006]. Impairment usually occurs as aresult of an elevated pressure of the aqueous humor fluid within the eye leading to gradual visual changes and finally blindness. A several known risk factors for glaucoma were reported, such as increased intraocular pressure (IOP), aging, family history, high myopia, systemic hypertension, cardiovascular disease, migraine headaches, peripheral vasospasm, and prior nerve damage (25). In addition to, other factors leading to glaucoma include; glutamate-induced neurotoxicity, nitric oxide-based damage, disruption of neurotrophic factor transport, and immune-induced neuro-destruction.

\section{Cataract}

Cataract is the opacity of the crystalline lens that interferes with normal vision; and considered as a leading cause of visual defect worldwide, specially for the elderly. Cataract as a multifactorial disease process is provoked by various toxic factors, environmental stressors, and gene mutations. Cataracts are known to be associated with damage or death of lens epithelial cells (LECs) [Li et al., 1994]. Cataract is the leading cause of blindness worldwide and covers around $42 \%$ of overall visual defect.

\section{Conjunctivitis}

Conjunctiva is a thin, translucent membrane lining the anterior part of the sclera and inside of the eyelids, conjunctivitis is the disease that occur due to the irritatation of mucous membrane on the inner surface of the eyelid [Bevans et al., 2004]. Conjunctivitis is the most common reason of red eye in primary care (26). Conjunctivitis can be produced by viruses, bacteria or fungi, exposure to chemicals or irritants, or a foreign body's long-term presence such as hard or rigid contact lenses (27).

\section{Dry eye disease}

Is one of the conditions most ever seen by eye care practitioners, and this is a direct reflection of the proportion of patients who suffer from dry eye symptoms (28). Dry eye disease is a multifactorial disorder of the tears and ocular surface that accompanied by various ocular symptoms and signs comprising; discomfort, visual disturbance, tear film instability, hyperosmolarity and ocular surface inflammation with potential impairment of the ocular surface (29)

\section{Diabetic retinopathy (DR)and antioxidants}

Diabetic retinopathy (DR) is a major complication of diabetes mellitus (DM), which remains a leading cause of blindness in working-age populations. The diagnosis of DR is made by clinical manifestations of vascular abnormalities in the retina. Clinically, DR is divided into two stages: non-proliferative diabetic retinopathy (NPDR) and proliferative diabetic retinopathy (PDR)(30).

Antioxidants are compounds that retard or prevent oxidation and prolong the life of the oxidizable matter. Free radicals are essential for any biochemical process and represent an essential part of aerobic life and metabolism. The majority of the diseases, are mainly linked to oxidative stress due to free radicals [Velavan et al., 2007]. These species may be either Oxygen derived (ROS) or nitrogen derived (RNS). The most common reactive oxygen species include superoxide anion $\left(\mathrm{O}_{2}\right)$, hydrogen peroxide $\left(\mathrm{H}_{2} \mathrm{O}_{2}\right)$, peroxyl radicals $(\mathrm{ROO})$, and reactive hydroxyl radicals $(\mathrm{OH})$. The nitrogen derived free radicals are nitric oxide (NO), peroxynitrite anion (ONOO), Nitrogen dioxide (NO2), and Dinitrogen trioxide $\left(\mathrm{N}_{2} \mathrm{O}_{3}\right)$ 
Evidences has suggests that oxidative stress is an important pathogenetic factor in the development of diabetic retinopathy (DR). Experimental data showed that the use of strategies that ameliorate oxidative stress can prevent and retard the development of DR in the animal model. Clinical observations also suggest that reducing oxidative stress may help to reverse pathological manifestations of DR (31-35).

Many studies postulated that Antioxidants have preventive effects on diabetic retinopathy, and much fruit intake is associated with a low incidence of diabetic retinopathy. Diabetic adults taking fruits and vegetables enriched with flavonoid had lower degrees of inflammation (36, 37), better glycemic control, and reduced diabetic retinopathy $(38-43)$

\section{Eye cancer}

The eye and adnexa are potential foci of neoplastic disease, either as primary sites or as sites of metastatic carcinoma. Eye cancer occurrence is rare combrable to other types of cancer, it is the only ocular disease which directly threatens life. The most common types include; intraocular melanoma for adults and retinoblastoma for children, whilst other types are; squamous cell CA, basal cell CA, ....etc. The survival rate of eye cancer is almost high (80\%) among persons receiving early treatment which nesseciate the importance of routine and early detection of such cases (44-47).

\section{D- Traditional eye medicines for common diseases}

Natural compounds are constituting of antioxidant or anti-inflammatory secondary metabolites anticataract agents. The role of plant polyphenols in anticataractogenic activities is also studied in a comprehensive manner, either in vitro or in vivo (48).

Total of 41 plants were investigated as anti-cataract activity(49)

66 plants were reported to treat conjunctivitis in folkloric medicine(50)

P.S. Sandhu and his co-workers (2011) screened $262 \mathrm{~m}$ plans for various ocular diseases, including different types of conjunctivitis, and revealed 51 were found to treat conjunctivitis(51).

A Multi-Center, Prospective, Randomized, Double-Blind, Placebo-Controlled Trial examining glass containing extracts of antioxidant medicinal plants against ocular surface disease using ocular surface disease index (OSDI) score and found them effective in improving in DED both subjectively and objectively. (52).

Medicinal plants and their bioactive compounds are used to control and normalize pathological cellular factors involved in Diabetic retinopathy (DR) progression(53)

Various phytoconstituents with retinal cytoprotective effects were investigated for their beneficial experimental and clinical evidence and highlighted their use for the management of (DR)(54).

Few plants were documented to treat eye cancer were reported by(55). Moreover, A natural plant compound showed a new era in treating eye cancer, such as uveal melanoma, according to researchers at Washington University School of Medicine (56) .

\section{The rationale of the Study}

Recently, there is an outbreak of using different medicinal plants to treat various ophthalmic disorders; these traditional use may potentially affect the future of ocular disorders management and development of new efficient and safe drugs. Studies that addressed these problems were scattered everywhere, which weakened its benefits. Thus the combination of these documents in a single manner is highly required which can be performed using modern research technique as systematic review with meta-analysis.

\section{Methodology}

\subsection{Asking a valid-answerable research question}

Although this review is a part of a project that provides a solid background, it intended to answer the question: "What are the Effect(s) of the medicinal plants on different common Ophthalmic disorders?" Or on other words: "What are the medicinal plants used for different common Ophthalmic disorders?'

\subsection{PICOS setup, Filter designing, optimization, and databases selection}

\subsubsection{Population (P)}

All published data (original research articles) on medicinal plants used to treat ophthalmic disorders from January 2011 to September 2021.

The study groups consisted of data in PubMed (The United States National Library of Medicine (NLM) at the National Institutes of Health), Science Direct (Elsevier's leading information solution for researchers) and the American Academy of ophthalmology during January 2011 to May 2021.

Studies included at all experimental levels (in-vitro, in-vivo, in-situ, and in-silico, etc.) and all study levels (observational, case-control, clinical trial, etc.).

\section{A-Inclusion criteria}

All original research articles on Medicinal plants that use to treat different ocular disorders (January 2011 to may 2021) in English. 
B-Exclusion criteria

All published data outside the time frame of the study period, Data published in other languages and data difficult to be re-synthetized.

\subsubsection{Intervention (I)}

The usage of different medicinal plants to treat patients with common ophthalmic disorders.

\subsubsection{Comparison(C)}

The different standard drugs or agents used for common ophthalmic disorders in clinical practice.

\subsubsection{Outcomes (0)}

Determine the plants' biological, therapeutic, and toxic effects on common ophthalmic disorders using a hazard ratio (HR) as outcomes measure.

\subsubsection{Study design (S)}

All types of studies; Experimental animal studies, Observational studies, Case-control studies, and clinical trials, will be assessed.

\subsection{Filter designing and optimization process}

Many trials of filter designing were carried out with a variety of outcomes; the optimum filters were selected for each database, including PubMed, Science Direct, and the American Academy of Ophthalmology

\subsubsection{Databases selection and Designing of the search plan}

PubMed was selected as the most famous database with numerous medical information, then a particular filter was used by joining the pre-determined PICOS using the built-in filter designing feature to retrieve the articles that were able to answer our question. After many trials to find the appropriate keywords for optimal search outcomes, these keyword terms were also combined using AND, OR to retrieve any relevant studies that had utilized the search method and narrow the research field.

The 2nd selected database for our study was Science direct as the biggest trusted; a special filter was designed to fit its criteria with the hope to retrieve the relevant studies that can answer our question.

The 3rd database was the American Academy of Ophthalmology (AAO.org). To design and optimize the filter, we trying different methods such as using the four advanced features (All words, None of these, Exact phrase, and Custom date range) using our search terms, then we try the direct search within the Journal of AAO (Ophthalmology) with either; Herb (112), or Plants (502) or Remedy (125) and finally we decide to use our specific phrase (Medicinal plants = 212) and the year 2021 was not available.

Different three persons carried out the search at the same time and then their results were compared, duplication removed and merged together and presented in one Prisma Chart.

\subsubsection{Data retrieval processusing online sources}

Unlike the conventional studies, this investigation used online sources for data retrieval by using the selected optimal filter for each database. The search outcomes were displayed in the form of an abstract, printed out, reviewed carefully, and checked for relevancy.

\subsubsection{Data screening process and manipulation in Prisma Flow Diagram}

The initially identified articles were screened on title and abstract to determine their appropriateness for inclusion. Studies categorized into Relevant (R) and non-Relevant (NR) articles were automatically excluded depending on the inclusion and exclusion criteria.

Articles written in another language rather than English were excluded based on language restrictions for this study.

The relevant studies based on their title or abstract, their full articles were retrieved using SDL facility or by self -communications overseas.

The standard Prisma flow chart diagram (The PRISMA Group) was used to conduct the main systematic review steps.

\subsubsection{Data extraction and Critical appraising of the included studies}

Full text of the relevant articles was reddened then each study's characteristics were extracted from all types of studies.

Data were extracted from relevant full-text articles, including; the name of the first author, publication year, country, population, plants type, plants number, interventions or exposures, comparison, Ethnobotanical indices, and their methods of estimation, outcomes and study design.

Methodological quality and risk of bias of the included studies were assessed according to the Cochrane collaboration criterion.(11)

\subsubsection{Calculation of effect size (ES) as endpoint for SR and starting point for MA}

A number of plants used for eye purposes in correlation to the total numbers of plants studied; besides, the pre-estimated indices were extracted from the included articles to calculate the effect size (ES); Odds ratio (OR) was obtained as outcomes measure, only one OR can be obtained from one study, then using 
Comprehensive Meta-analysis version 2 to join with ES of other articles in the quantitative analytical part of the study (Meta-analysis).

For the Observational Experimental Studies, ES is calculated as standardized mean difference $(d)$, The standardized mean difference between two groups (mainly control and experiment), calculated by subtract the mean of one group (Experiment) from the other (control) and divide the result by the standard deviation (SD) of control group should be taken, the formula as follows:

$\boldsymbol{d}(\mathrm{ES})=\left(\frac{\operatorname{Mean}(E)-\operatorname{Mean}(C)}{S D}\right)$

\subsubsection{Data Presentation}

All the data were presented as descriptive statistics using various forms of figure including Forest plot

\subsubsection{Statistical analysis}

The findings extracted from all articles were gathered into tables and analyzed using Comprehensive Meta-analysis version 2 (CMA) as statistical software. Forest plots were obtained to display the pooled effect. Its confidence interval after combining all studies, relative weight and residual were extracted from the forest plot.

Clinical and methodological heterogeneity were checked qualitatively by using the study and methodology characteristics of the included studies. During Meta-analysis, the homogeneity and heterogeneity among studies were checked using (CMA) program and common meta-analysis models (Fixed-effect, Random-effect and both) to combine the studies. While the following parameters were used:Q-value, I squared $\left(I^{2}\right)$ or Higgins $\left.\right|^{2}$, Tau squared $\left(\right.$ Tau $\left.{ }^{2}\right)$, P-value (of 0.10 , rather than the conventional level of 0.05 ) was used to determine statistical significance.

Sub-groups analysis was performed base on study designs and epigenetic modifications to find the causes of heterogeneity among the studies.

The publication bias among studies was checked using (CMA) program using a funnel plot to ensure any bias among the studies enrolled in this study. All the data were presented as descriptive statistics using various figures, including forest plots and funnel plots and tables.

Sensitivity analysis was done by (CMA) program by changing study designs, statistical models, and one study removal analysis method.

The Null hypothesis: $\mathrm{H}_{0}$ : Are the effect size is equal in all of the studies Or (Are the effect sizes homogeneous) was tested by assuming that all studies in the meta-analysis share a common (true) effect size. The result will be discussed based on whether there was a significant association between the different studies population that allowed their possibility to be joined in the overall population.

\section{Results}

\subsection{Qualitative synthesis (Systematic review) results}

\subsubsection{Search strategy outcomes}

Different filters designed based on PICOS returned the following results:

\section{A-Optimum filter for PubMed}

)(((((()(((((Plant [Title/Abstract]) OR (Herb [Title/Abstract]) AND (Glaucoma [Title/Abstract]) OR (Cataract [Title/Abstract]) OR (Conjunctivitis [Title/Abstract]) OR (Dry Eye [Title/Abstract]) OR (Retinopathy [Title/Abstract]) OR (Eye tumor [Title/Abstract]) AND (Eye [Title/Abstract]) OR (Ocular [Title/Abstract]) OR (Ophthalmic [Title/Abstract]) AND (Effect [Title/Abstract]) AND (Biological [Title/Abstract]) OR (Therapeutic [Title/Abstract]) AND ("last 10years" [Tit(e/Abstract])))))))))))))): 904 results.

\section{B- Optimum filter for Science direct}

(Medicinal Plant OR Herbal Remedy) and (Eye OR Ophthalmic OR Ocular) and (Disorders OR Diseases) and (Effect assessment) and (Last 10 Years)

1833results.

C- Optimum filter for American Academy of Ophthalmology (Ophthalmology Journal)

Medicinal Plants: 212results.

\subsubsection{Qualitative results presentation as Prisma flow chart}

\subsubsection{Interpretation of Prisma flow chart results}

\section{A- Identification}

Records identified from searching were $(n=2949)$ as the following: 
PubMed $=904$ articles.

These retrieved articles were carefully screened through their title and then abstracts, and only nine were found to be relevant, and their full texts were retrieved and were categorized as follow; 7 are review, 1 is a book chapter, and 1 is in the French language. Thus all were excluded from the re-synthesis next step.

Science direct $=1833$ articles .

These retrieved articles were carefully screened through their title and then abstracts. Only 35 were found to be relevant. Their full texts were retrieved and categorized as follows; 28 are reviewed, thus excluded, and the rest seven articles were eligible for re-synthesis next step.

American Academy of Ophthalmology $(\mathrm{AAO})=212$ articles.

These articles were retrieved through the previous search strategies. Then only original articles and fall within the pre-determined time range were screened, where two duplicated articles were excluded, and 19 articles were used in the next step, These findings were presented in Fig. 1.

\section{B-Screening}

As mentioned in the method, the screening step was followed to determine their appropriateness for inclusion. Studies are categorized into Relevant ( $R$ ) and non-Relevant (NR). After applying inclusion and exclusion criteria, the NR records were equal (2146) and excluded automatically.

\section{C-Eligibility}

Full articles were obtained and read to ensure theirrelevancy. Full-text articles assessed for eligibility were equal to 35 articles. Full-text articles excluded were 28 articles due to non-relevant to the topic or not the primary source (review articles or book Chapter). Moreover, the non-relevancy is due to one of the following reasons; Surgical maneuvers, Medical investigations, Other cancer typess, Synthetic drugs, Radiation therapy, Therapeutic regimen plans \& protocols, Epidemiological studies, and outcomes evaluation or Herbal treatment for other diseases.

\subsubsection{Included studies, characteristics extracted and Critical appraisal}

Studies included in qualitative synthesis systematic review equal to 4 articles. Data extracted from full-text of all articles included in the systematic review are shown in Table 1, 2, 3 \& 4, respectively.

\subsection{Critical appraising of the included studies}

Methodological quality and risk of bias are assessed, the assessment includes; Adequacy and clearness of representativeness of the selected participants to the target population, Measurement of exposure or intervention, Measurement of outcomes, Control of confounding, while the Incomplete outcome data and follow-up were not applicable for this study type and only suite for Cohort ones as seen in Tables 1, 2, 3 \& 4 for analytical observational cross-sectional and Experimental studies.

Table 1: Data extraction from full-text articles from Analytical Cross-sectional (Survey) studies. 


\begin{tabular}{|c|c|c|c|c|c|c|c|c|c|}
\hline $\begin{array}{l}\text { Types of } \\
\text { Study } \\
\text { (name of } \\
\text { the first } \\
\text { author and } \\
\text { date of } \\
\text { publication) }\end{array}$ & Country & Populations & $\begin{array}{l}\text { Plants } \\
\text { type }\end{array}$ & Number & $\begin{array}{l}\text { Interventions } \\
\text { or } \\
\text { Exposures }\end{array}$ & Comparison & $\begin{array}{l}\text { Ethnobotanical } \\
\text { Indexes } \\
\text { \& Methods }\end{array}$ & Outcomes & Study design: \\
\hline $\begin{array}{l}\text { K. Rehman } \\
\text { et al. (2015) } \\
\text { (Rehman, } \\
\text { Mashwani } \\
\text { et al. 2015) }\end{array}$ & Pakistan & Informants & Mixed & 66 & Eye use & $\begin{array}{l}\text { tested } \\
\text { experimentally } \\
\text { for validation }\end{array}$ & $\begin{array}{l}\text { Relative } \\
\text { frequency } \\
\text { citation (RFC) } \\
\text { Medicinal use } \\
\text { value (MUV) } \\
\text { Informal } \\
\text { conversation } \\
\text { + semi- } \\
\text { structured } \\
\text { interviews }\end{array}$ & $\begin{array}{l}\text { exploring the } \\
\text { rarely or never } \\
\text { reported plants }\end{array}$ & $\begin{array}{l}\text { Documentatic } \\
\text { of } \\
\text { Ethnobotanic } \\
\text { Knowledge }\end{array}$ \\
\hline $\begin{array}{l}\text { B. Novotna, } \\
\text { et al. (2020) } \\
\text { (Novotnaa, } \\
\text { Polesnya et } \\
\text { al. 2020) }\end{array}$ & Angola & $\begin{array}{l}\text { professional } \\
\text { herbalists }\end{array}$ & $\begin{array}{l}\text { Indigenous } \\
\text { and Exotic }\end{array}$ & 87 & Eye use & $\begin{array}{l}\text { Sub-Saharan } \\
\text { Africa }\end{array}$ & $\begin{array}{l}\text { use reports } \\
\text { (UR) }\end{array}$ & $\begin{array}{l}\text { new } \\
\text { ethnomedicinal } \\
\text { uses } \\
\text { absence of } \\
\text { pharmacological } \\
\text { studies } \\
\text { the same use in } \\
\text { neighboring } \\
\text { countries }\end{array}$ & $\begin{array}{l}\text { Traditional } \\
\text { botanical } \\
\text { knowledge }\end{array}$ \\
\hline $\begin{array}{l}\text { I. Sile, et al. } \\
\text { (2020)(Sile, } \\
\text { Romane et } \\
\text { al. 2020) }\end{array}$ & Latvia & Records & $\begin{array}{l}\text { Native and } \\
\text { imported } \\
\text { plants }\end{array}$ & 211 & Eye use & $\begin{array}{l}\text { European } \\
\text { Union herbal } \\
\text { monographs }\end{array}$ & $\begin{array}{l}\text { Card index } \\
\text { Use reports } \\
\text { (UR) }\end{array}$ & $\begin{array}{l}\text { Unreported } \\
\text { plants }\end{array}$ & $\begin{array}{l}\text { Ethnobotanic } \\
\text { knowledge }\end{array}$ \\
\hline $\begin{array}{l}\text { Khajuria, } \\
\text { A.K.' } \\
(2020) \\
\text { (Khajuria, } \\
\text { Manhas et } \\
\text { al. 2021) }\end{array}$ & India & Informants & Wild & 236 & Eye use & Local flora & $\begin{array}{l}\text { Informant } \\
\text { Consensus } \\
\text { Factor (ICF) } \\
\text { Frequency of } \\
\text { citation (FC) } \\
\text { Use reports } \\
\text { (UR) }\end{array}$ & $\begin{array}{l}\text { Disease } \\
\text { treatment } \\
\text { category }\end{array}$ & $\begin{array}{l}\text { Ethnobotanic } \\
\text { study }\end{array}$ \\
\hline
\end{tabular}

Table 2: Extraction data from full-text articles, the 3 studies were used throughout the quantitative study part

\begin{tabular}{|c|c|c|c|c|c|c|}
\hline Serial & Study & Population & Intervention & Comparison & Outcome & Design \\
\hline 1 & $\begin{array}{l}\text { N.A. Stefanova et al., } \\
\text { 2011(A.Stefanova, Zh. } \\
\text { et al. 2011) }\end{array}$ & $\begin{array}{l}\text { OXYS and } \\
\text { Wistar rats }\end{array}$ & $\begin{array}{l}\text { Effect of } \\
\text { Cistanchedeserticola (CD) } \\
\text { herba }\end{array}$ & Wisterrats & $\begin{array}{l}\text { Cataract and retinopathy } \\
\text { development in senescent } \\
\text { accelerated OXYS rats (severity) }\end{array}$ & $\begin{array}{l}\text { Observational } \\
\text { study }\end{array}$ \\
\hline 2 & J. Song et al., 2013 & $\begin{array}{l}\text { Rats \& } \\
\text { Rabbits }\end{array}$ & $\begin{array}{l}\text { SIN released as a function } \\
\text { of time from various } \\
\text { formulations }\end{array}$ & $\begin{array}{l}\text { Gel group }(0.5 \% \\
\text { SIN) } \\
\text { VS } \\
\text { control group } \\
(0.5 \% \text { SIN })\end{array}$ & $\begin{array}{l}\text { cumulative Drug amount of SIN } \\
\text { released }\end{array}$ & $\begin{array}{l}\text { Observational } \\
\text { study }\end{array}$ \\
\hline 3 & T.-Y. Hong et al., 2016 & $\begin{array}{l}\text { streptozotocin } \\
\text { (STZ) diabetic } \\
\text { rats }\end{array}$ & $\begin{array}{l}\text { Protective effect of } \\
\text { ethanol extract from } \\
\text { Zingiber zerumbet on DR }\end{array}$ & $\begin{array}{l}\text { EEZZR-treated } \\
\text { diabetic rats. } \\
\text { VS } \\
\text { calcium } \\
\text { dobesilate }(C D)- \\
\text { treated diabetic } \\
\text { rats. }\end{array}$ & $\begin{array}{l}\text { DR protective effects } \\
\text { The retinal blood vessel } \\
\text { permeability } \\
\text { The expression rate of vascular } \\
\text { endothelial growth factor (VEGF) } \\
\text { Expressions rate of renal } \\
\text { pigment epithelium-derived } \\
\text { factor (PEDF) in diabetic rats }\end{array}$ & $\begin{array}{l}\text { Observational } \\
\text { study }\end{array}$ \\
\hline
\end{tabular}

Table 3: Critically appraise the study in the case of Cross-sectional studies. 


\begin{tabular}{|c|c|c|c|c|c|}
\hline $\begin{array}{l}\text { Study } \\
\text { Name of the First author, } \\
\text { Year of publication }\end{array}$ & $\begin{array}{l}\text { representativeness of the } \\
\text { selected participants to the } \\
\text { target population }\end{array}$ & $\begin{array}{l}\text { Measurement of exposure } \\
\text { or intervention }\end{array}$ & $\begin{array}{l}\text { Measurement of } \\
\text { outcomes }\end{array}$ & $\begin{array}{l}\text { Control of } \\
\text { confounding }\end{array}$ & $\begin{array}{l}\text { Incomplete } \\
\text { outcome data and } \\
\text { follow-up * }\end{array}$ \\
\hline \multirow{2}{*}{$\begin{array}{l}\text { K. Rehman et al. (2015) } \\
\text { (Rehman, Mashwani et al. } \\
\text { 2015) }\end{array}$} & Adequate & Inadequate & \multirow[t]{2}{*}{ Clear } & \multirow[t]{2}{*}{ Adequate } & \multirow[t]{2}{*}{ NA } \\
\hline & More than 100 and elderly & $(4.5 \%)$ & & & \\
\hline \multirow{2}{*}{$\begin{array}{l}\text { B. Novotna, et al. (2020) } \\
\text { (Novotnaa, Polesnya et al. } \\
\text { 2020) }\end{array}$} & \multirow{2}{*}{$\begin{array}{l}\text { Inadequate (10 informants for } 2 \\
\text { areas) }\end{array}$} & Adequate & Inadequate & \multirow[t]{2}{*}{ Inadequate } & \multirow[t]{2}{*}{ NA } \\
\hline & & $(14.9 \%)$ & $\begin{array}{l}\text { Other relevant } \\
\text { indices were not } \\
\text { applied }\end{array}$ & & \\
\hline \multirow{4}{*}{$\begin{array}{l}\text { I. Sile, et al. (2020)(Sile, } \\
\text { Romane et al. 2020) }\end{array}$} & \multirow[t]{4}{*}{ Adequate } & \multirow{2}{*}{$\begin{array}{l}\text { Inadequate }(1.9 \%) / \text { plants } \\
\text { number }\end{array}$} & Inadequate & Inadequate & \multirow[t]{4}{*}{ NA } \\
\hline & & & \multirow{3}{*}{$\begin{array}{l}\text { Other relevant } \\
\text { indices were not } \\
\text { applied }\end{array}$} & \multirow{3}{*}{$\begin{array}{l}\text { More archive } \\
\text { details are } \\
\text { required }\end{array}$} & \\
\hline & & Adequate (56.5\%) & & & \\
\hline & & (MUR) & & & \\
\hline $\begin{array}{l}\text { Khajuria, A.K ., (2020) } \\
\text { (Khajuria, Manhas et al. } \\
\text { 2021) }\end{array}$ & Adequate & $\begin{array}{l}\text { Adequate for other use, } \\
\text { but Inadequate for Eye use } \\
(1.7 \%)\end{array}$ & Clear & Adequate & NA \\
\hline
\end{tabular}

Table 4:The methodological quality of the included studies.

\begin{tabular}{|c|c|c|c|c|c|c|}
\hline Serial & Study & $\begin{array}{l}\text { Selection of } \\
\text { comparison }\end{array}$ & $\begin{array}{l}\text { Measurement of } \\
\text { intervention }\end{array}$ & $\begin{array}{l}\text { Measurement of } \\
\text { outcome }\end{array}$ & $\begin{array}{l}\text { Control of } \\
\text { confounding }\end{array}$ & $\begin{array}{l}\text { Incomplete } \\
\text { outcome data }\end{array}$ \\
\hline 1 & $\begin{array}{l}\text { N.A. Stefanova et al., 2011(A.Stefanova, Zh. et } \\
\text { al. 2011) }\end{array}$ & Adequate & Adequate & Clear & & \\
\hline 2 & $\begin{array}{l}\text { J. Song et al., } 2013 \text { (Jike Song, Hongsheng Bi } \\
\text { et al. 2013) }\end{array}$ & Adequate & Adequate & Clear & & \\
\hline 3 & $\begin{array}{l}\text { T.-Y. Hong et al., } 2016 \text { (Tang-Yao Hong, Thing- } \\
\text { Fong Tzeng et al. 2016) }\end{array}$ & Adequate & Adequate & Clear & & \\
\hline
\end{tabular}

\subsubsection{Detailed interpretation of Prisma flow chart results of quantitative synthesis}

Studies included in the qualitative synthesis review are equal to 4 articles, reporting Odds' ratios (OR) in outcome measures. These articles were used in the final analysis (Meta-analysis), see Table 1.

Article No. 1: (20)

They documented an ethnobotanical knowledge of a neglected restricted Pakistani area to expose them for experimental testing and scientific validation. Conducing Informal conversation followed by semi-structured interviews and using Relative frequency citation (RFC) and Medicinal use-value (MUV) to categorize the medicinal uses of these plants.

Article No.2: (21)

They interviewed an Angolian professional herbalist with knowledge and compared their findings with the Sub-Sahran Africa using Use Report (UR). There are some use in neighboring countries, new ethnomedicinal uses, and the absence of pharmacological studies.

Article No. 3: (22)

They investigated and evaluated Latvian records containing native and imported plants and compared them to the European Union herbal monographs using Card Index and Use Report techniques. Many unreported plants were found with significant efficacy and safety.

Article No. 4: (23)

Khajuria and his co-workers evaluated the Indian informant's response regarding the 236 wild plant use traditionally compared to the local flora. Although, The plants used for eye diseases possess application of different quantitative ethnobotanical indices, only four plants were with eye use.

\subsection{Articles included in Meta-analysis and preparation of different articles outcome (ES calculation)}

Table 5: Effect size calculation of outcomes from the four eligible studies for the quantitative part. 


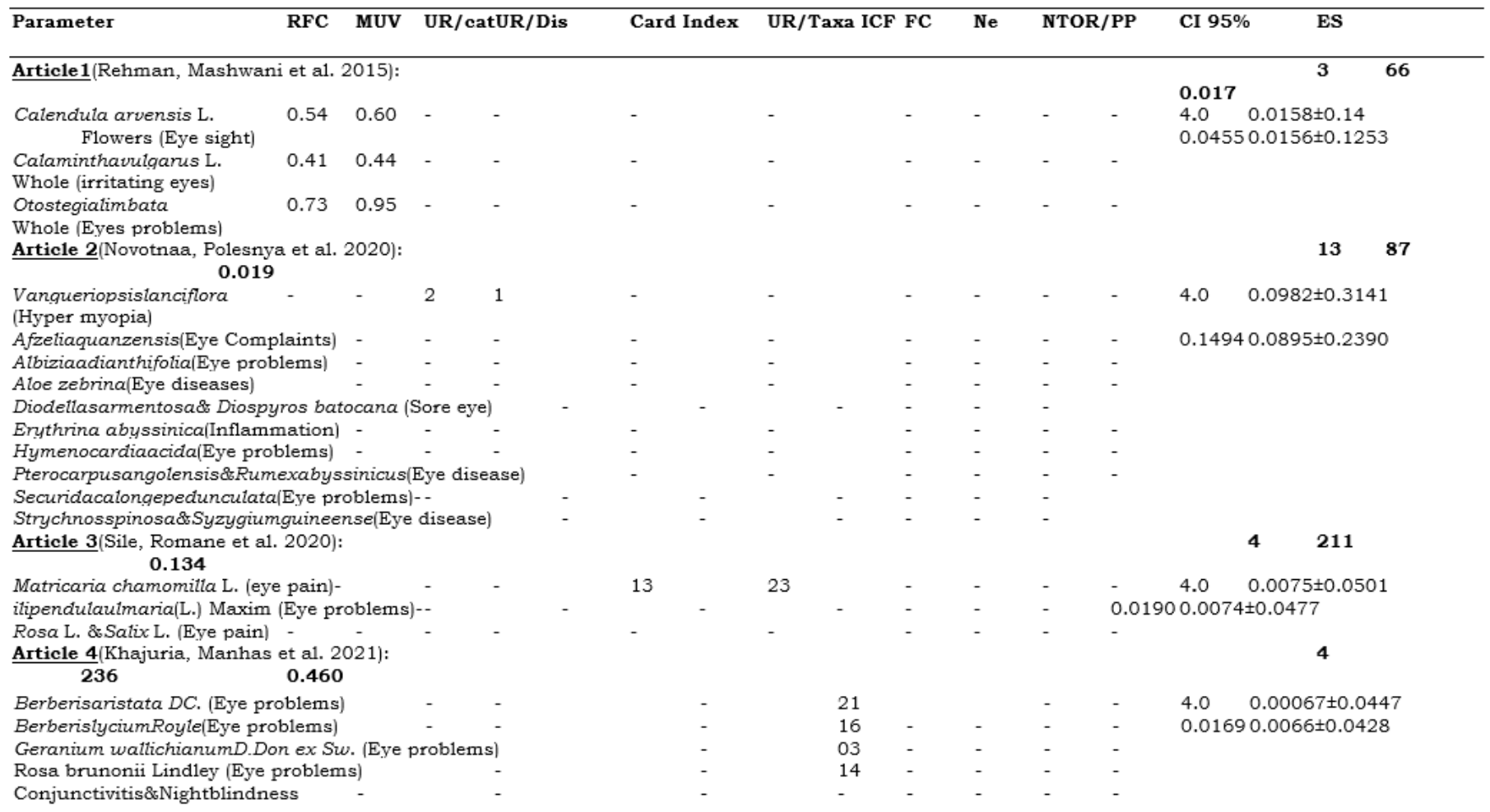

RFC: Relative Frequency Citation, MUV: Medicinal Use value, UR/cat: Use report/Category, UR/Dis: Use report/Disease, Card Index, UR/Taxa: Use report/plant Taxa, ICF: Informant Consensus Factor, FC: Frequency Citation, Ne: number of plants used for eye disease, NT: Total number of plants in the article, PP/OR: Estimated Population Proportion/Odds ratio, Cl 95\%: Confidence Interval level with its Lower \& upper limits, ES: Estimated Effect size.

Table 6: Effect size calculated from the raw data presented in table 5.

\begin{tabular}{|c|c|c|c|c|}
\hline \multirow{2}{*}{\multicolumn{2}{|c|}{$\begin{array}{l}\text { Parameter Experimental (E) } \\
\text { Article 1(A.Stefanova, Zh. et al. 2011) }\end{array}$}} & Control (C) & \multicolumn{2}{|c|}{ Differences (E-C) ES } \\
\hline & & & & \\
\hline Cataract severity & 0.25 & 0.29 & 0.04 & \\
\hline Retinopathy severity & 0.46 & 0.29 & 0.17 & \\
\hline Mean & 0.355 & 0.29 & 0.105 & \\
\hline SD & 0.105 & 0.00 & 0.065 & 1.62 \\
\hline \multicolumn{5}{|c|}{ Article 2:(Jike Song, Hongsheng Bi et al. 2013) } \\
\hline \multicolumn{5}{|c|}{ Pharmacokinetic parameters of SIN in aqueous humor } \\
\hline \multicolumn{2}{|l|}{ AUC $(\mu \mathrm{g} m 1-1 \mathrm{~h})$} & $13.46 \pm 2.32$ & 22.81 & $\mathbf{7 . 7 8}$ \\
\hline $\mathrm{Cmax}(\mu \mathrm{g} \mathrm{ml}-1)$ & $0.27 \pm 0.02$ & $0.15 \pm 0.024$ & 0.120 & 6.00 \\
\hline $\mathrm{Tmax}(\mathrm{min})$ & 40 & 40 & 0.000 & 0.00 \\
\hline $\mathrm{t} 1 / 2(\mathrm{~min})$ & $81.64 \pm 6.61$ & $65.94 \pm 4.32$ & 15.70 & 2.87 \\
\hline MRT(0-8) (h) & $124.16 \pm 7.62$ & $100.89 \pm 8.33$ & 23.27 & 2.92 \\
\hline \multicolumn{5}{|c|}{ Article 3:(Tang-Yao Hong, Thing-Fong Tzeng et al. 2016) } \\
\hline \multicolumn{5}{|c|}{ DR protective effects: (inhibition of) } \\
\hline \multicolumn{5}{|c|}{ A-The retinal blood vessel permeability $(\mathrm{ng} / \mathrm{mg})$} \\
\hline \multicolumn{2}{|l|}{ STZ-diabetic rats } & $2.8 \pm 1.5$ & 10.4 & 6.71 \\
\hline \multirow{2}{*}{$\begin{array}{l}\text { CD-Treatment STZ-DR } \\
\text { EEZZR }\end{array}$} & $7.8 \pm 1.4$ & $2.8 \pm 1.5$ & 05.0 & 3.45 \\
\hline & $6.2 \pm 1.2$ & $2.8 \pm 1.5$ & 03.4 & 1.35 \\
\hline \multicolumn{5}{|c|}{ B-Expression rate of vascular endothelial growth factor (VEGF) } \\
\hline \multicolumn{2}{|c|}{ STZ-diabetic rats (mRNA) $30.8 \% \downarrow$} & $100 \%$ & 69.2 & \\
\hline EEZZR (Protein) & $35.7 \% \downarrow$ & $100 \%$ & 64.3 & \\
\hline \multirow{2}{*}{$\begin{array}{l}\text { Mean } \\
\text { SD }\end{array}$} & 33.25 & 100 & 66.75 & \\
\hline & 2.45 & 0.00 & 2.45 & 27.2 \\
\hline \multicolumn{5}{|c|}{ C-Expressions rate of retinal pigment epithelium-derived factor (PEDF) } \\
\hline \multirow[t]{2}{*}{ VEGF-to-PEDF ratio } & $61.4 \% \downarrow$ & 100 & 38.6 & \\
\hline & 3.1 -fold $\uparrow$ & 100 & 200.2 & \\
\hline
\end{tabular}


Article 1: (57)

Regarding the DR, The severity reduction rate for Control group (1.39 \pm 0.09 to $1.68 \pm 0.07)$ and for treated group $(1.00 \pm 0.07$ to $1.46 \pm 0.10)$, while for cataract control group ( $1.71 \pm 0.1$ to $1.42 \pm 0.10)$ and $(1.29 \pm 0.11$ to $1.54 \pm 0.11)$ for treated one, see Tables $5 \& 6$.

Article 2: (58)

The Pharmacokinetic main parameters of SIN in aqueous humor were estimated as a parameter for a cumulative amount release of SIN from the gel formula. Then the ES was calculated as a standardized mean, see Tables 5 \& 6 .

Article 3: (59)

Different protective parameters were estimated and compared, such as; The retinal blood vessel permeability (ng/mg), the Expression rate of vascular endothelial growth factor (VEGF), and Expressions rate of retinal pigment epithelium-derived factor (PEDF) and furtherly used to estimate the ES using standardized mean, see Tables 5 \& 6 .

\subsection{Quantitative study (Meta-analysis)}

\subsubsection{Compilation for all study outcomes: The medicinal plants used for Ocular disorders}

All four analytical observational Cross-sectional studies with calculated effect size were analyzed together, and the following results were obtained.

\section{A-The forest plot information}

The forest plot for both fixed and random models showed that most studies indicated the prediction tendency of plant used status (see Fig. 2).

\section{B-The relative study wieghts and their residuals results}

The fixed model showed that the third study(22) has the highest relative weight (55.8\%) with a high residual, while the rest of the studies possess relative weight of (15.7\%), moreover random model treats all the studies in a similar manner, see Fig. 3.

\section{C- Heterogeneity parameters results}

\section{C- The clinical heterogeneity}

Although all the included studies were particular cross-sectional and Experimental types, no clinical heterogeneity among studies can be estimated.

\section{C- Statistical heterogeneity}

The variability tests showed high heterogeneity, estimated as $\mathrm{I}^{2}=87.078, \mathrm{Tau}^{2}=1.161$ and Q-value $=23.217$ with $\mathrm{p}$-value of 0.000 for observational studies and $\mathrm{I}^{2}=94.928, \mathrm{Tau}^{2}=23.211$ and Q-value $=39.434$ with $\mathrm{p}$-value of 0.000 , as shown in Table 7.

Table 7: Heterogeneity parameters extracted from forest plot of the Medicinal plants used for Ocular disorders to detect heterogeneity.

\begin{tabular}{|c|c|c|c|c|c|c|c|}
\hline \multirow[b]{2}{*}{ Q-value } & \multicolumn{6}{|c|}{ Heterogeneity tests } & \multirow[b]{2}{*}{ Tau } \\
\hline & $\mathrm{df}(\mathrm{Q})$ & P-value & $\mathbf{I}^{2}$ & $\mathrm{Tau}^{2}$ & Standa & r Variance & \\
\hline \multicolumn{8}{|c|}{ A- Observational: } \\
\hline 23.217 & 4 & 0.000 & 87.078 & 1.161 & 1.159 & 1.343 & 1.077 \\
\hline \multicolumn{8}{|c|}{ B- Experimental: } \\
\hline 39.434 & 3 & 0.000 & 94.928 & 23.211 & 28.166 & 793.342 & 4.818 \\
\hline
\end{tabular}

Q; Cochran statistic, df;

\section{D- The funnel plot information for publication bias}

The majority of the Observational Ethnobotanical studies were scattered outside the funnel and segregated at the bottom, while only one study was segregated inside the funnel, both two, red and blue diamond showed identical dimensions of the pooled effect estimated and the true effect,

On the other hand, the Observational Experimental studies were segregated inside the funnel, some at the bottom and one on the top. Both red and blue diamonds showed identical dimensions of the pooled effect estimated and the true effect, as shown in Fig. 4.

E-Solutions for heterogeneity problems: $\left(\mathrm{I}^{2}=87.078\right.$ and $\left.\mathrm{I}^{2}=94.928\right)$ for both study types 
The common solution is Sub-group analysis based on study design types or The Sensitivity analysis studies for prediction tendency check by changing both statistical models and study designs or by one-study removal. These solutions cannot work because the available data did not contain sub-group data either different study design types.

\section{Discussion}

Recently, there is a lack of studies that address these problems, and few available ones were scattered everywhere, which weaken its benefits. Thus the combination of these documents in a single manner is highly required. The finding of natural, safe-effective medicinal plants to be involved in Ocular disorders treatment for better cure is an tremendous challenge for the next few years.

\subsection{Filter design and optimization}

Our study used three different well-designed filters that enable us to search in the three selected medical databases as no single database is comprehensive in its coverage of published research, which indicate that, databases diversity were precisely considered during the filter designing in order to cover all the study inclusion criteria appropriately and to focus searches on the best quality research evidence upon which to make decisions.

Moreover, our observations revealed that some databases were highly selective to the keywords, and the search results retrieved were significantly related to the PICOS, but others can give a lot of un-related studies.

Only primary studies were included, which were retrieved by the well-designed filters. This means that our study clearly targeted the originality to re-synthesize and compile its findings because the parameters were estimated directly. This inline with Theresa et. al.(60)

Several non-English articles were excluded due to language restriction, which performed automatically during searching or the scanning process. This can be taken as evidence for the presence of some sort of publication bias. Morrison and his co-workers reported that no significant differences were found between summary treatment effects in English-language restricted meta-analyses and languages other than English meta-analyses(61)

The search was done during the last ten years in the selected databases from January 20211 to May 2021, which represent the most recent articles, the old articles published before 2011 were not included due to time restriction. Also, unpublished studies were not involved; this can lead to some bias that changes the results of this review.

Our search observed that most of the retrieved articles were either non-relevant or reviewed or book chapters in nature which were excluded by default.

Although the included studies were few, they represent and cover the main three Continents; Asia, Africa, and Europe. This empowers their information and can lead to reasonable conclusions that reflect the word status regarding the addressed issue.

\subsection{Critical appraisal of the selected studies}

From total of 2949 , only four articles( $0.14 \%)$ were reached by the end of the systematic review steps. This means that the majority of the available literature were under the requirement of this study.

Our systematic review results revealed that all the studies were observational cross-sectional studies with mild to moderate quality, this seen during the critical appraisal and before it, which indicate the general rules in which these study types was the ranked 2nd or third top of the scientific evidence pyramid (62)

The filtered articles were critically appraised to minimize bias as far as possible because there are many differences among studies regarding their quality.

The Ethnobotanical surveys can be considered as a particular type of Observational studies and widely used in the field of plants evaluation, and they may be of Knowledge or documentation purposes using different approaches, this in line with Bernard, 2002(18), while the quantitative ones that apply indices which allow re-synthesis were rare

\subsection{The qualitative part: systematic review}

Our systematic literature search on the use of medicinal plants for ocular disorders revealed that few articles address this issue. This indicates the lack of these data type among the retrieved articles.

Although, a few numbers of research in this area, since the retrieved studies were detected current status and only four ethnobotanical studies were resynthesized(20-23) and the weakness of these studies can be overcome by using a diachronic approach, that suggests limiting the sample size but repeating the studies every few years as suggested by (19). Whilst 3 Experimental studies were re-synthesized using a power-full ES estimated from the Standardized mean of control and treated groups, this confirm by Dunlap et. al., 1996 (63), who reported that the best one was to used standardized mean difference directly when the correlation between measures is not provided as we did in this study following the equation $(d=(M E-M C) / S D)$

\subsection{The quantitative part: Meta-analysis}

\section{A-Studies compilation using forest plot tool}

Our meta-analysis of both fixed and random models summarized in the forest plot provides that, all 4 studies contain few numbers of plants with eye use, ; therefore it can be used to reflect this gloomy area. 
The pooled effect Odds ratio obtained by the forest plot was less than 1, which means that the ocular use of medicinal plants has potential importance among other uses. This results agree with most studies in this area.

\section{B-The determination among studies heterogeneity}

A high level of significant heterogeneity among our pooled studies was reported as $\left(I^{2}=87.078\right)$. The heterogeneity test indicates that the null hypothesis must be rejected, which states the homogeneity among the studies, and the accepted alternative hypothesis. This heterogeneity may be attributable to our inclusion criteria which allow a wide methodological diversity among studies to be involved. This includes variability in our search strategies term (PICOS).

Regarding the high heterogeneity,our obsevations revealed significant heterogeneity among compiled studies $(P=0.000)$, which requiredfurther addition of articles that might be done by channgeing the time framework and serach term to determine the origin of this heterogeneity.

\section{C- The publication bias using funnel plot tool}

The funnel plot of our results showed some sort of publication bias appear as scattered and asymmetrically distributed of the studies. This indicates that publication bias was found either due to selective outcome reporting or unpublished research excluded from this review. The asymmetry of the funnel plot may be due to other reasons rather than publication bias, such as poor methodological quality of smaller studies and true heterogeneity as mentioned by Cochrane collaboration. (11)

\section{Conclusion And Future Perspectives}

More data search for studies addressing is an issue are needed to elucidate the natural, safe-effective ocular therapeutic agent(s )for the upcoming cascade.

Functional studies will need to be extended to in vivo testing in animal models. Finally, large-scale studies of human tissues with good clinical recordslarge large-scale studies of human tissues with good clinical records will need to be performed to put the in vitro and animal studies into a firm of clinical context.

We can conclude that search strategies should include several databases and unique filter should be used for every database, besides changing the search terms for commonly used ones

This topic is an interesting research area of high level of novelty and lack of data. Thus new studies should focus on it

\section{Limitations And Recommendations}

We strongly recommend that this review must be repeated to include the old published articles in the old years that not included in our review, also unpublished, non-English studies and data from other databases should be involved to cover all studies conducted in the area of this review to cover all these scarce information areas.

Other terms such as; Alternative and complementary medicine must be used to widen the scope and retrieve more relevant studies.

The following are some of the limitations of this review which can serve as future interesting research points; The articles are limited to certain countries, Meta-analysis only done for the original research of observational study and not the review articles which were available is high among different databases.

Comparative Quantitative Ethnobotanical studies must be encouraged to re-synthesis of their results outcomes and be more applicable and beneficial.

Clinical trials for different medicinal plants should be started immediately to stand against different diseases, particularly ocular ones.

\section{Declarations}

\section{Ethics approval and consent to participate}

As per Al Baha university standards, all the funded projects proposals must underwent critical review followed by aprooval by the The Scientific Research Affirs relevant committes before acceptance.

\section{Consent for publication}

Not Applicale.

\section{Availability of data and materials}

All data generated or analysed during this study are available with Dr. Ali as the correspondence author and can be provided upon request.

\section{Competing interests}

The authors declare that they have no competing interests.

Funding 
This study was supported by the Ministry of Education Program of KSA (NO: MOE-BU-4-2020). The funders played no role in the design of the study, data collection and analysis, or preparation of the manuscript.

\section{Authors' contribution}

Ali conceived the original idea, Mahadi, Hiadar and Aimun, designed and collected the data, Aimun analyzed the data and drafted the manuscript, and Ali, Asaad and Gul revised it. All approved the final version that was submitted. All were equally contributed. All authors approved the version to be published and agreed to be accountable for all aspects of the work.

\section{Acknowledgment}

This article is a part of the funded project: Investigation of Medicinal Plants with Putative Ocular Effects from Al Baha Area, Southwestern, Saudi Arabia, Grant number (MOE-BU-4-2020), thus the funder body is highly acknowledged for their financial support.

\section{References}

1. Crowther MA, Cook DJ. Trials and tribulations of systematic reviews and meta-analyses. Hematology Am Soc Hematol Educ Program. 2007:493-7.

2. Cook DA, West CP. Conducting systematic reviews in medical education: a stepwise approach. Med Educ. 2012;46(10):943-52.

3. Sharma R, Gordon M, Dharamsi S, Gibbs T. Systematic reviews in medical education: a practical approach: AMEE guide 94. Med Teach. 2015;37(2):10824.

4. Wells K, Littell JH. Study Quality Assessment in Systematic Reviews of Research on Intervention Effects. Res Soc Work Pract. 2009;1(1):52-62.

5. . !!! INVALID CITATION !!! (5).

6. Olivo SA, Macedo LG, Gadotti IC, Fuentes J, Stanton T, Magee DJ. Scales to assess the quality of randomized controlled trials: a systematic review. Phys Ther. 2008;88(2):156-75.

7. O'Connor AM, Sargeant JM. Critical appraisal of studies using laboratory animal models. ILAR J. 2014;55(3):405-17.

8. Lundh A, Gotzsche PC. Recommendations by Cochrane Review Groups for assessment of the risk of bias in studies. BMC Med Res Methodol. $2008 ; 8: 22$.

9. M. Viswanathan, M. T. Ansari, N. D. Berkman, S. Chang, L. Hartling, M. McPheeters, et al. Assessing the Risk of Bias of Individual Studies in Systematic Reviews of Health Care Interventions. 2012.

10. D. O'Connor, S. Green, Higgins JP. Defining the Review Question and Developing Criteria for Including Studies. 2008.

11. Higgins JP. Cochrane Handbook for Systematic Reviews of Interventions 5.1.0, no. version 5.1.0.(Update march 2011). . The cochrane collabration. 2011.

12. M. A. Pourhoseingholi, A. R. Baghestani, M. Vahedi. How to control confounding effects by statistical analysis. Gastroenterol Hepatol from Bed to Bench, 2012;5(2): 79-83.

13. Verhagen AP, Ferreira ML. Forest plots. J Physiother. 2014;60(3):170-3.

14. Israel H, Richter RR. A guide to understanding meta-analysis. J Orthop Sports Phys Ther. 2011;41(7):496-504.

15. Martin GJ. Ethnobotany. A "People and Plants" Conservation Manual. . World Wide Fund for Nature. 1995;Chapman \& Hall, London.

16. Sekagya Y, Hills. LF, G. E. Traditional Medicine. In: A Clinical Guide to Supportive and Palliative Care for HIV/AIDS in Sub-Saharan Africa. Editors: Part 3: Psychosocial/Spiritual and Traditional Care. 2006;Chabterr 15(Washington, DC: Health Resources and Services Administration.): pp219-32.

17. Balandrin MF, Kinghorn AD, Farnsworth NR. Plant-Derived Natural Products in Drug Discovery and Development. . 1993; In: Kinghorn, A.D., Balandrin,M.F. (Eds.), Human Medicinal Agents from Plants, ACS Symposium series 534 American Chemical Society DC,:pp. 2-12.

18. Bernard HR. Research methods in anthropology: Qualitative and quantitative approaches. . Walnut Creek, CA: Altamira. 2002.

19. VOGL CR, VOGL-LUKASSER B. Tools and Methods for Data Collection in Ethnobotanical Studies of Homegardens. Field Methods 2004;16(3):285-306.

20. Rehman K, Mashwani ZU, Khan MA, Ullah Z, Chaudhary HJ. An ethno botanical perspective of traditional medicinal plants from the Khattak tribe of Chonthra Karak, Pakistan. J Ethnopharmacol. 2015;165:251-9.

21. Novotnaa B, Polesnya Z, Pinto-Bastoc MF, Dammea PV, Pudila P, Mazancovae J, et al. Medicinal plants used by 'root doctors', local traditional healers in Biéprovince, Angola. Journal of Ethnopharmacology 2020;260 112662.

22. Sile I, Romane E, Reinsone S, Maurina B, Tirzite D, Dambrova M. Medicinal plants and their uses recorded in the Archives of Latvian Folklore from the 19th century. J Ethnopharmacol. 2020;249:112378.

23. Khajuria AK, Manhas RK, Kumar H, Bisht NS. Ethnobotanical Study of Traditionally used Medicinal Plants of Pauri District of Uttarakhand, India. J Ethnopharmacol. 2021:114204.

24. Klotz SA, Penn CC, Negvesky GJ, Butrus SI. Fungal and parasitic infections of the eye. Clin Microbiol Rev. 2000;13(4):662-85.

25. Friedman DS, Wilson MR, Liebmann JM, Fechtner RD, Weinreb RN. An evidence-based assessment of risk factors for the progression of ocular hypertension and glaucoma. Am J Ophthalmol. 2004;138(3 Suppl):S19-31.

26. Alfonso SA, Fawley JD, Alexa Lu X. Conjunctivitis. Prim Care. 2015;42(3):325-45.

27. Sethuraman U, Kamat D. The red eye: evaluation and management. Clin Pediatr (Phila). 2009;48(6):588-600.

28. O'Brien PD, Collum LM. Dry eye: diagnosis and current treatment strategies. Curr Allergy Asthma Rep. 2004;4(4):314-9.

29. Herrero-Vanrell R, Peral A. [International Dry Eye Workshop (DEWS). Update of the disease]. Arch Soc Esp Oftalmol. 2007;82(12):733-4. 
30. Romero-Aroca P, Baget-Bernaldiz M, Pareja-Rios A, Lopez-Galvez M, Navarro-Gil R, Verges R. Diabetic Macular Edema Pathophysiology: Vasogenic versus Inflammatory. J Diabetes Res. 2016;2016:2156273.

31. Williams M, Hogg RE, Chakravarthy U. Antioxidants and diabetic retinopathy. Curr Diab Rep. 2013;13(4):481-7.

32. Wu Y, Tang L, Chen B. Oxidative stress: implications for the development of diabetic retinopathy and antioxidant therapeutic perspectives. Oxid Med Cell Longev. 2014;2014:752387.

33. Madsen-Bouterse SA, Kowluru RA. Oxidative stress and diabetic retinopathy: pathophysiological mechanisms and treatment perspectives. Rev Endocr Metab Disord. 2008;9(4):315-27.

34. Arden GB, Sivaprasad S. Hypoxia and oxidative stress in the causation of diabetic retinopathy. Curr Diabetes Rev. 2011;7(5):291-304.

35. Galetovic D, Bojic L, Bucan K, Karlica D, Lesin M, Znaor L. The role of oxidative stress after retinal laser photocoagulation in nonproliferative diabetic retinopathy. Coll Antropol. 2011;35(3):835-40.

36. Tanaka S, Yoshimura Y, Kawasaki R, Kamada C, Horikawa C, Ohashi Y, et al. Fruit intake and incident diabetic retinopathy with type 2 diabetes. Epidemiology. 2013;24(2):204-11.

37. Mahoney SE, Loprinzi PD. Influence of flavonoid-rich fruit and vegetable intake on diabetic retinopathy and diabetes-related biomarkers. J Diabetes Complications. 2014;28(6):767-71.

38. Ola MS, Al-Dosari D, Alhomida AS. Role of Oxidative Stress in Diabetic Retinopathy and the Beneficial Effects of Flavonoids. Curr Pharm Des. 2018;24(19):2180-7.

39. Khan AA, Rahmani AH, Aldebasi YH. Diabetic Retinopathy: Recent Updates on Different Biomarkers and Some Therapeutic Agents. Curr Diabetes Rev. 2018;14(6):523-33.

40. Al-Dosari DI, Ahmed MM, Al-Rejaie SS, Alhomida AS, Ola MS. Flavonoid Naringenin Attenuates Oxidative Stress, Apoptosis and Improves Neurotrophic Effects in the Diabetic Rat Retina. Nutrients. 2017;9(10).

41. Zhang T, Mei X, Ouyang H, Lu B, Yu Z, Wang Z, et al. Natural flavonoid galangin alleviates microglia-trigged blood-retinal barrier dysfunction during the development of diabetic retinopathy. J Nutr Biochem. 2019;65:1-14.

42. Nabavi SF, Habtemariam S, Daglia M, Shafighi N, Barber AJ, Nabavi SM. Anthocyanins as a potential therapy for diabetic retinopathy. Curr Med Chem. 2015;22(1):51-8.

43. Liu L, Zuo Z, Lu S, Liu A, Liu X. Naringin attenuates diabetic retinopathy by inhibiting inflammation, oxidative stress and NF-kappaB activation in vivo and in vitro. Iran J Basic Med Sci. 2017;20(7):813-21.

44. Kleinstein RN, Lehman HF. Incidence and prevalence of eye cancer. Am J Optom Physiol Opt. 1977;54(1):49-51.

45. Marshall EC. Epidemiology of tumors affecting the visual system. Optom Clin. 1993;3(3):1-16.

46. Kaneko A. [Malignant ophthalmic tumors]. Nihon Rinsho. 1993;51 Suppl:1013-20.

47. Witmer R. [Intraocular tumors (author's transl)]. Schweiz Rundsch Med Prax. 1981;70(24):1091-4.

48. Tewari D, Samoila O, Gocan D, Mocan A, Moldovan C, Devkota HP, et al. Medicinal Plants and Natural Products Used in Cataract Management. Front Pharmacol. 2019;10:466.

49. Thiagarajan R, Manikandan R. Antioxidants and cataract. Free Radic Res. 2013;47(5):337-45.

50. Sharma P, Singh G. A review of plant species used to treat conjunctivitis. Phytotherapy Research 2002;16(1):1-22.

51. Sandhu PS, Singh B, Gupta V, Bansal P, Kumar D. Potential Herbs Used in Ocular Diseases /J Pharm Sci \& Res 2011;3(4):1127-40.

52. Choi W, Kim JC, Kim WS, Oh HJ, Yang JM, Lee JB, et al. Clinical Effect of Antioxidant Glasses Containing Extracts of Medicinal Plants in Patients with Dry Eye Disease: A Multi-Center, Prospective, Randomized, Double-Blind, Placebo-Controlled Trial. PLoS One. 2015;10(10):e0139761.

53. Parveen A, Kim JH, Oh BG, Subedi L, Khan Z, Kim SY. Phytochemicals: Target-Based Therapeutic Strategies for Diabetic Retinopathy. Molecules. 2018;23(7).

54. Ojha S, Balaji V, Sadek B, Rajesh M. Beneficial effects of phytochemicals in diabetic retinopathy: experimental and clinical evidence. Eur Rev Med Pharmacol Sci. 2017;21(11):2769-83.

55. Matowa PR, Gundidza M, Gwanzura L, Nhachi CFB. A survey of ethnomedicinal plants used to treat cancer by traditional medicine practitioners in Zimbabwe. BMC Complement Med Ther. 2020;20(1):278.

56. Strait JE. Scientists identify weak point in deadly eye melanoma. https://sourcewustledu/2018/09/scientists-identify-weak-point-in-deadly-eyemelanoma/. 2018 Acsessed: 21 May 2021.

57. A.Stefanova N, Zh. A, N. F, Nataliya S, G.Kolosova. Effects of Cistanche deserticola on behavior and signs of cataract and retinopathy in senescenceaccelerated OXYS rats. Journal of Ethnopharmacology. 2011;138(2): 624-32

58. Jike Song, Hongsheng Bi, Xiaofeng Xie, Junguo Guo, Xingrong Wang, Liu D. Preparation and evaluation of sinomenine hydrochloride in situ gel for uveitis treatment Int Immunophar. 2013;17(1):99-107.

59. Tang-Yao Hong, Thing-Fong Tzeng, Shorong-Shii Liou, Liu I-M. The ethanol extract of Zingiber zerumbet rhizomes mitigates vascular lesions in the diabetic retina. Vascular Pharmacology 2016;76:18-27.

60. Charrois TL. Systematic reviews: What do you need to know to get started? Can J Hosp Pharm. 2015;68(2):144-8.

61. A. Morrison, J. Polisena, D. Husereau, K. Moulton, M. Clark, M. Fiander, et al. The Effect of English-Language Restriction on Systematic Review-Based Meta-Analyses: a Systematic Review of Empirical Studies. Int J Technol Assess Health Care. 2012;28( 02):138-44.

62. M Hassan Murad, Noor Asi, Mouaz Alsawas, Alahdab F. New evidence pyramid. Evid Based Med. 2016;21(3):125-7.

Page $15 / 18$ 
63. William P. Dunlap, Jose M. Cortina, Joel B. Vaslow, Burke MJ. Meta-Analysis of Experiments With Matched Groups orRepeated Measures Designs. Psychological Methods. 1996;1(2):170-7.

\section{Figures}

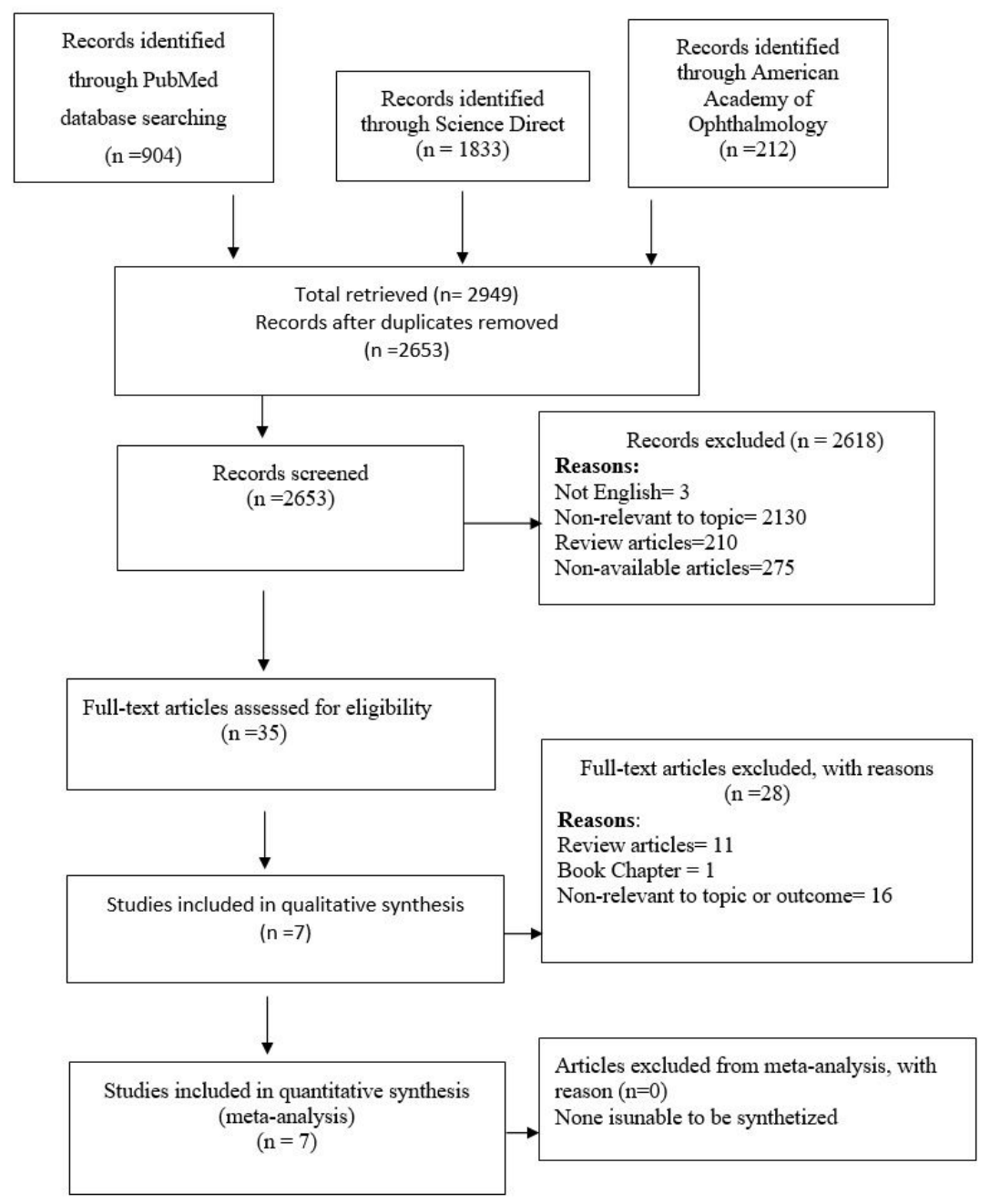

Figure 1

Prisma Flow chart results of inclusion/exclusion of the individual studie 


\section{Meta Analysis}

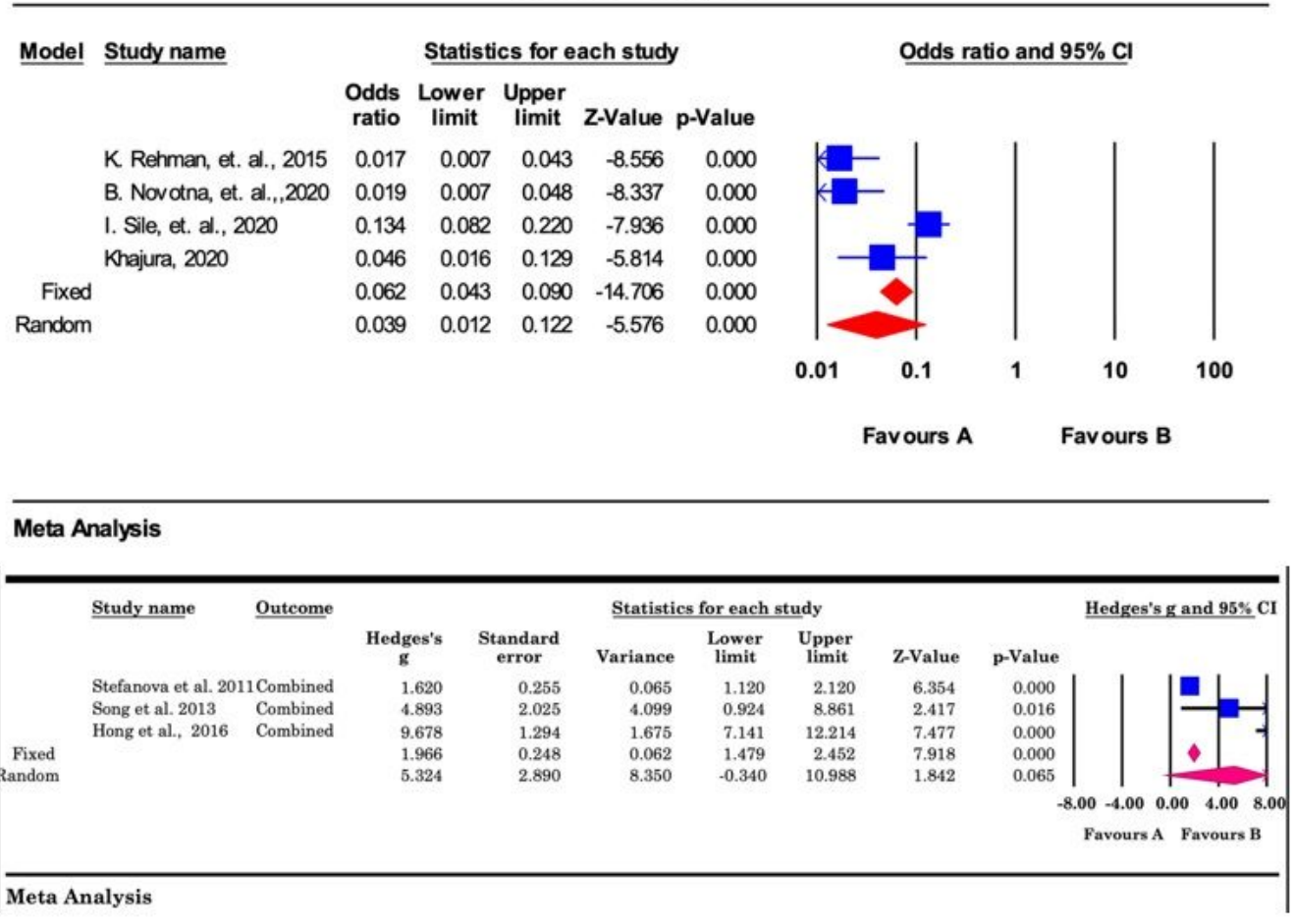

\section{Figure 2}

The forest plot of 4 observational studies (A) represents their Effect size on medicinal plants used for different eye disorders. For each study, the odds ratio and it's $95 \% \mathrm{Cl}$ was plotted with a blue square and horizontal line using both fixed and random-effect models, while OR =1; no prediction, OR> or $\otimes 1$; prediction regardless the direction. whilst the 3 experimental studies (B) as plants use outcome. For each study, the standardized mean difference and its $95 \% \mathrm{Cl}$ from 4 repeated measures was plotted with a circles and horizontal line using both fixed and random-effect model.

\begin{tabular}{||l|l|c|c|c|c|}
\hline Model & Study name & Weight (Fixed) & Weight (Random) & Residual (Fixed) & Residual (Random) \\
& & Relative weight & Relative weight & Std Residual & Std Residual \\
& K. Rehman, & 15.73 & 24.41 & -2.97 & -0.81 \\
& B. Novotna, & 15.83 & 24.44 & -2.71 & -0.70 \\
& I. Sile, et. & 55.77 & 27.67 & 4.58 & 1.31 \\
Khajura, & 12.66 & 23.48 & -0.62 & 0.15 \\
Fixed & & & & & \\
Random & & & & & \\
\hline
\end{tabular}

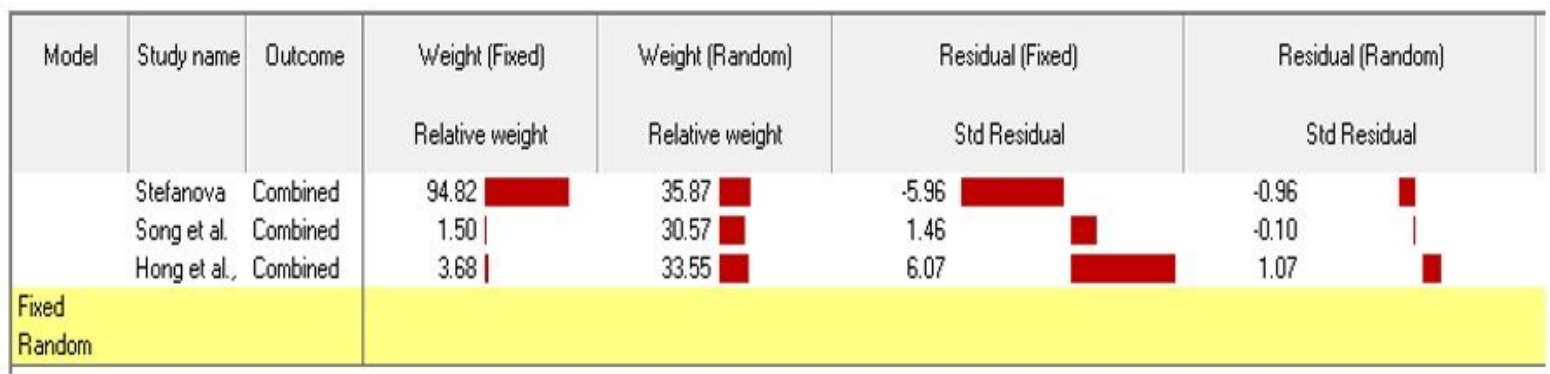

\section{Figure 3}

The relative weights and residuals of the (A) Observational and (B) Experimental studies extracted from forest plots of the Medicinal plants used for different ocular disorders using both fixed and random-effect meta-analysis models. 

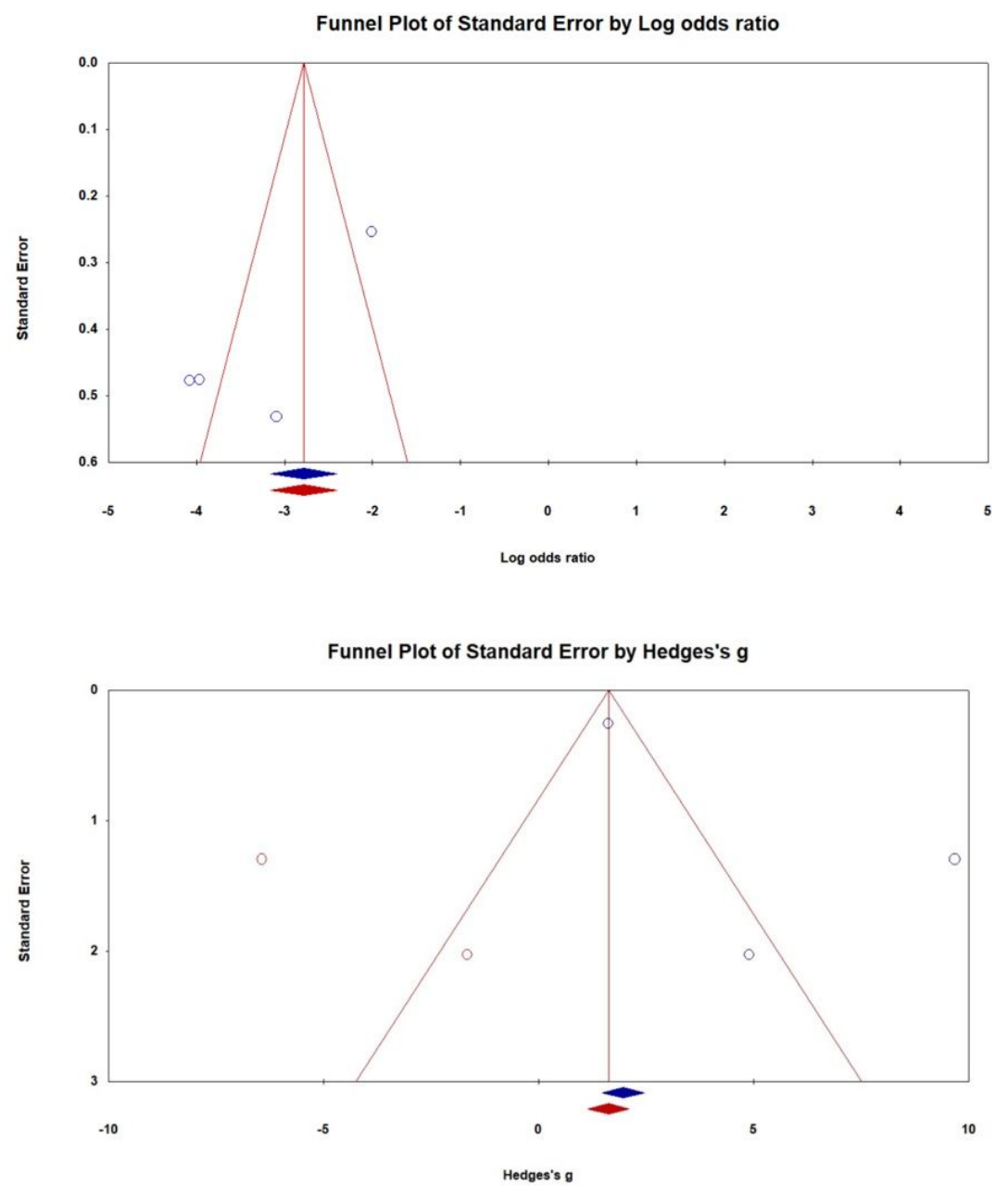

\section{Figure 4}

The funnel plot of 4 observational studies(A) and 3 Experimental studies (B), represents the publication bias of all studies. Graph plotted the standard error versus the log of either Odds ratio or Hedge's g, diamonds shape illustrates the summary of both observed (blue) and imputed (red) hazard ratio of all studies. Each small blue circle indicates an individual study. 